\title{
Using Online Program Development to Foster Curricular Change and Innovation
}

\author{
Anne E. Gwozdek, R.D.H., B.A., M.A.; Emily C. Springfield, B.A., M.S.Ed.; \\ Melissa R. Peet, Ph.D.; Wendy E. Kerschbaum, R.D.H., M.A., M.P.H.
}

Abstract: Distance education offers an opportunity to catalyze sweeping curricular change. Faculty members of the University of Michigan Dental Hygiene Program spent eighteen months researching best practices, planning outcomes and courses, and implementing an e-learning (online) dental hygiene degree completion program. The result is a collaborative and portfolio-integrated program that focuses on the development of reflective practitioners and leaders in the profession. A team-based, systems-oriented model for production, implementation, and evaluation has been critical to the program's success. The models and best practices on which this program was founded are described. Also provided is a framework of strategies for development, including the utilization of backward course design, which can be used in many areas of professional education.

Prof. Gwozdek is Clinical Lecturer and Director, Dental Hygiene Degree Completion Programs, Periodontics and Oral Medicine, University of Michigan; Ms. Springfield is Instructional Technology Designer, Dental Informatics, University of Michigan; Dr. Peet is Assistant Research Scientist, Periodontics and Oral Medicine, University of Michigan; and Prof. Kerschbaum is Director of Dental Hygiene, Periodontics and Oral Medicine, University of Michigan. Direct correspondence and requests for reprints to Prof. Anne E. Gwozdek, Periodontics and Oral Medicine, University of Michigan, 1011 N. University, Room 3066, Ann Arbor, MI 48109; 734-615-7749 phone; 734-763-5503 fax; agwozdek@umich.edu.

Keywords: curricular change, distance education, systems-oriented model, backward course design, integration, active learning, reflection, portfolios, dental hygiene, online baccalaureate degree

Submitted for publication 7/16/10; accepted 9/23/10

$\mathrm{O}$ ver the past decade, the American Dental Education Association Commission on Change and Innovation in Dental Education (ADEA $\mathrm{CCI}$ ) has led an initiative for curricular change and innovation in dental education designed to keep pace with the rapid changes in science, technology, and oral health care delivery. Educational research supports new theory and methodology focusing on enhancing student learning. No longer can an educational delivery method that is fifty years old be the standard. ${ }^{1}$ The ADEA CCI articulated the necessity for educators to become change agents to advance and sustain curricular reform and innovation. ${ }^{2}$

Dental hygiene curricular reform is an important component of this change process. In this era when most dental hygienists have an associate degree, greater emphasis is now being placed on the baccalaureate degree. Allowing for the furthering of academic credentials, a baccalaureate degree provides education that focuses the roles of the dental hygienist beyond clinician, including those of educator, researcher, administrator/manager, advocate, and public health practitioner. ${ }^{3}$
The University of Michigan (U-M) entry-level dental hygiene program confers a bachelor of science in dental hygiene degree. Additionally, for over a quarter century, U-M has had an on-campus degree completion program. This program's courses, held during the weekday hours and offered in Ann Arbor, MI, provided limited options for those not located near campus. Upon investigation of the literature related to curricular change along with research affirming distance education as a viable delivery option, the U-M Dental Hygiene Program initiated the systematic development of an e-learning (online) degree completion program in July 2006. This program, which was launched in January 2008, is premised upon models and best practices for collaborative and portfolio-based learning, as well as a focus on developing reflective practitioners and lifelong learners. The models and best practices upon which this program was founded are described in this article, offering a framework of strategies for development that can be utilized in many areas of professional education. 
Degree completion programs provide an education bridge, offering the opportunity for those dental hygienists with associate degrees or certificates to complete the additional credit hours to obtain a baccalaureate degree. Increasing health care competence demands and expanded general education, biomedical sciences, and dental/dental hygiene sciences accreditation expectations have caused associate degree dental hygiene programs to significantly expand their curricula. ${ }^{4,5}$ Currently, a dental hygiene student who graduates with an associate degree completes nearly three-quarters of the credits needed for a baccalaureate degree. Beginning in the late 1980s, studies began to emerge supporting the interest of the dental hygiene community in a bachelor's degree and identifying geographic locations of programs, desire to retain employment, and limited flexibility in course scheduling as barriers for students in pursuing advanced education. ${ }^{4,6}$ The need has been further documented by the demand for dental hygiene faculty members, ${ }^{7,8}$ a desire for responsibility in addressing the oral health needs of the nation, and the need for expanded dental hygiene research. ${ }^{7}$

Yet, of the 314 accredited entry-level programs in the United States, 84 percent (265) confer an associate degree. ${ }^{9}$ Of the sixty dental hygiene bachelor's degree completion programs, only nineteen are offering course content 100 percent online. ${ }^{10}$ More recently, Grimes confirmed the major themes supporting technology-based education as increasing student access, maintaining regular employment during advanced educational completion, and providing flexibility of curriculum while responding to student demand. ${ }^{11}$ In response to these professional needs, faculty members in the U-M Dental Hygiene Program spent eighteen months researching, planning, and implementing an e-learning (online) dental hygiene degree completion program.

\section{Systems-Oriented Model: A Basis for Initiating Change}

The systems-oriented model of instructional development assumes that a large amount of instruction will be developed with a team of individuals. ${ }^{12}$ Diamond, in 1989, developed this model specific to higher education, focusing on a team approach for comprehensive curricula offerings. Emphasis is placed on analyzing goals prior to development; in fact, front-end analysis usually takes as much time and effort as implementation and revision. We began the development process for our program with the identification of E-Learning Program Development Team members, including a team leader to coordinate and manage the effort. The team utilized key concepts to guide this process:

1. Keep the end in mind: what is the end objective/ vision for each stage/step? (e.g., What skills should students have when they graduate?)

2. Use best practices: what are the best practices relevant to each step, question, phase, or issue, and how will these be used in a conceptual model to guide online learning?

3. Make decisions based on feasibility: including time and logistical considerations for students and faculty, what campus support and technology used to enhance student learning are needed, based on the skills needed and those to be built and incorporating reflective practice?

Diamond's model is also sensitive to organizational priorities and missions, incorporating input from university personnel and faculty. It is divided into two phases: 1) project selection and design and 2) production, implementation, and evaluation. ${ }^{12}$

The E-Learning Program Development Team began phase one (project selection and design) by benchmarking issues such as prospective students, curriculum content, institutional support, and faculty expertise/enthusiasm (Table 1). Goals, timeline, resources, and student needs were also components of phase one. Format for delivery and determination of course content were identified by the team. During phase two (production, implementation, and evaluation), individual course development occurred in small groups following the systems-oriented model with its step-by-step process of prototyping and revisions.

\section{Phase One: Project Selection and Design}

With the need for degree completion curricular change and innovation identified and the determination that distance education was an effective solution (project selection), the design component of phase one moved forward. This focused on benchmarking, which included an environmental scan of the dental hygiene profession and its future goals, degree completion education, best practices related to distance education, and resources available to support and sustain an online program. Literature 
Table 1. Systems-oriented model: University of Michigan Dental Hygiene Degree Completion E-Learning Program

Phase One: Project Selection and Design

- Team: director of dental hygiene, e-learning program director, director of dental informatics

- Timeline: six months

- Tasks accomplished:

- Identified change and innovation needed for the dental hygiene degree completion program.

- Established distance education as an educationally effective solution to meet those needs.

- Determined institutional and faculty support.

- Researched best practices.

- Developed framework for e-learning program; identified delivery method/technology.

- Developed framework for program marketing, admissions, and faculty development.
Phase Two: Production, Implementation, and Evaluation

- Team: dental hygiene program director, e-learning program director, six dental hygiene faculty members, instructional technology designer

- Timeline: twelve months

- Tasks accomplished:

- Developed program competencies.

- Designed curriculum according to competencies.

- Designed first three courses and portfolio program; these courses were implemented beginning in January 2008. Additional eight courses were developed and phased in over the next eighteen months.

- Developed/implemented faculty development program.

- Developed formative and summative program evaluation program.

- Launched marketing program.

- Admitted first cohort to the program. and experiences from the nursing profession's efforts to provide education in an online format provided guidance as well. ${ }^{13}$ From this process, cornerstones emerged that assisted in developing the program framework: format, technology, curriculum, marketing, admissions, and faculty development. When applying these cornerstones to other programs, the specific decisions in each area will likely vary from the solutions described here; however, it is important that each cornerstone be addressed according to the unique needs of the program in question.

\section{Program Format}

Underlying framework. The program was developed based on the concept addressed in Monson et al. that a strong degree completion program incorporates coursework from each of the American Dental Hygienists' Association (ADHA) six focus areas (research, education, licensure and regulation, practice and technology, public health, and government), positioning dental hygienists for leadership roles. ${ }^{7}$ Successful development of degree completion programs considers the educational venue (faceto-face versus distance) that will enable the largest number of dental hygienists to pursue a baccalaureate degree. ${ }^{7}$
Course delivery format. Asynchronous course delivery, allowing participants to not be online at the same time, was determined to best meet the needs of prospective students. This also addressed the issues of students' personal flexibility and the ability to remain employed. This delivery mechanism allows students to work within their own work/study schedules rather than having to adhere to predetermined class meeting times. Although more convenient, asynchronous course delivery demands that participants must utilize effective reading and writing skills in order to communicate effectively. ${ }^{14}$

In a study of first- and second-year students from eight associate degree-granting institutions in Minnesota, over half expressed interest in advanced education (57.6 percent). ${ }^{7}$ In addition, 32 percent of those interested in degree completion were willing to commit two years for the coursework. Therefore, a two-year, part-time, thirty-six-credit hour curriculum (six credit hours per semester) was developed for the e-learning program. Because of the complexities of a degree completion student's need to balance education, personal, and practice-related responsibilities, the U-M courses were based on seven-week "minimesters." This allowed for two three-credit minimester courses to be completed within a traditional semester, with the student enrolled in one course at a 
time, each with its own intensive seven-week content focus. Also taken into account was that many students would be interested in remaining eligible for financial aid, and at this institution, enrollment in six credit hours per semester allows students to be considered for part-time aid.

Structure of learning community and evaluation. Research indicated that cohorts create an environment of mutual intellectual and academic stimulation, form social ties that can become lasting professional contacts, and allow for more streamlined organization/administration of a program..$^{15}$ Thus, a cohort-based approach was adopted that would matriculate students through the program as a group within a prescribed period of time.

Strategic development of the learning community itself was considered in light of the asynchronous delivery format chosen. Scheduling at least one face-to-face meeting among students and faculty is recommended for distance learning programs ${ }^{16} \mathrm{An}$ orientation event was determined by the development team to be a good opportunity for students to meet each other, interact with the faculty, and receive an introduction to e-learning-related technology and program resources.

It was important that a comprehensive program evaluation plan be established up front that would collect both qualitative and quantitative data from all stakeholders. Thus, evaluation would need to be integrated throughout the program with analysis of outcomes assessment taking place on a regular basis in order to make modifications and/or changes to improve student learning outcomes.

\section{Other Aspects of Program Development}

Technology. A critical component of the benchmarking process was evaluation of technology and support services available at U-M. Courses would need to be placed on secured websites that would allow for both students and faculty to function in an academic environment. The university utilizes an open-source course management system
(CMS), CTools, developed by the Sakai community. Reliable technology is critical to a successful online program. ${ }^{17}$ To minimize student computer problems, it was determined that students would be required to purchase a warrantied laptop specified by the elearning program. The Office of Dental Informatics within the School of Dentistry was involved in the front-end analysis of technology resources and support for an online program.

Assessing trends in dental hygiene degree completion curricula. To assess trends in online dental hygiene degree completion education and develop goals for the e-learning program, the development team contacted eight program directors at other institutions. Discussion focused on types of technology used, technological support, students enrolled, faculty responsibilities/compensation, and curriculum focus. The team also used the 2005 ADHA report Dental Hygiene: Focus on Advancing the Profession, which provided a framework for dental hygiene education and practice. ${ }^{18}$ These discussions and resources not only assisted in shaping the program format and technology decisions; they were instrumental in developing the U-M e-learning program goals (Table 2) and eleven-course (thirty-six credit hour) curriculum framework (Table 3). Important curricular elements included the creation of an active learning environment, using technology to enhance student learning, and providing course content supporting self-directed learning and critical thinking.

Marketing. Consideration of the time-sensitive issue of informing prospective students about the new e-learning program was also addressed during the benchmarking and program development phase. Advertisement of the program was placed in dental hygiene publications, and program information was provided to ADHA for placement on its website. Vendor tables were hosted at dental hygiene professional association events, and personal visits were made to faculty and students at community colleges. Distributable program information was mailed to all dental hygiene program directors in the United States. Tracking of prospective student inquiries, applicants, and admissions based on where students

Table 2. University of Michigan Dental Hygiene Degree Completion E-Learning Program goals

Goal 1: Develop leaders in the dental hygiene profession.

Goal 2: Prepare dental hygienists to work as members of multidisciplinary health care teams and in alternative practice settings.

Goal 3: Prepare dental hygienists for expanded roles and career opportunities. 
found information about the e-learning program was initiated.

Admissions. Distance education students require a specific skill set for online success including a reasonable level of computer literacy. ${ }^{17}$ Maximizing the successful student completion rate of the program was also a focus of program development. Research showed that a decision to remain in or drop out of an online program can be complex, but the highest number of students leave after completing the first course. ${ }^{19}$ Reasons such as technology skills limitations, communication issues, and understanding of the time commitment have been cited as contributing factors. ${ }^{19}$ It was determined that the e-learning admissions process needed to focus not only on students' academic qualifications and technology skills but also a clear understanding of the role of the student in an online environment. A pre-interview worksheet was developed asking applicants to assess the time they have available weekly to participate in their coursework (eighteen hours/week) and determining if they have the appropriate technology and management skills to engage in online learning. An online computer skills check (SkillCheck by First Advantage) is administered to assess a student's proficiency in navigating the Internet and using Microsoft Office software. An interview (by phone or in person) with the e-learning program director was also included in the admissions process to allow for personal discussion about the results of these assessments and

\section{Table 3. E-learning program curriculum}

Semester 1 - Leadership and Professional Development (3 credits): Lifelong learning is an essential element of professionalism. This course will focus on current issues in dental hygiene and how individuals can contribute to the advancement of the profession and promotion of oral health for the public.

- Oral Diseases: Prevention and Management (3 credits): This course is designed to facilitate critical thinking skills related to specific oral diseases and the relationship between oral health and systemic health. The prevention and management of selected oral conditions are emphasized.

Semester 2 - Health Promotion and Risk Reduction (3 credits): Students will gain an understanding of the concepts of health, well-being, and health behaviors and their relationship to the care of patients. In the course, students will analyze and evaluate attitudes, beliefs, and behaviors related to health and illness in individuals, families, and communities across the lifespan.

- Research/Evidence-Based Practice (3 credits): This course focuses on the components of scientific inquiry with application to oral health research. Students will learn how to access information electronically, evaluate the professional literature, and use this information for evidence-based decision making in dental hygiene practice. Students will develop skills for scientific presentations.

Semester 3 - Community I (3 credits): In this course, the student will develop advanced skills in the area of community-based program planning, implementation, and evaluation. Defining oral health problems and solutions is emphasized. Students will also begin to develop a community-based program, to be implemented in Community II.

- Special Populations (3 credits): Segments of the U.S. population with the greatest unmet oral health needs often include those persons with special needs. This course will examine the specific challenges associated with access to care, patient assessment, and the provision of oral health services for these individuals.

Semester 4 - Community II (3 credits): In this field experience in a community setting, students will implement a communitybased program utilizing program planning and evaluation skills. Health promotion and risk reduction strategies in the community are emphasized.

- Dental Hygiene Education (3 credits): There is a critical need for teachers in dental hygiene programs, and this course will introduce students to the concepts and theory of teaching. Strategies for classroom, laboratory, and clinical teaching will be included.

Semester 5 - Practicum (3 credits): This course provides students with a mentored teaching experience. The teaching practicum offers the opportunity to apply the concepts and theory of teaching studied in the Dental Hygiene Education course. Placements may include classroom, online, laboratory, and/or clinical experiences.

- Capstone I (3 credits): This course is the planning phase for the student's final course, Capstone II/ePortfolio, and involves the development of a capstone project. This project will focus on students' application of their knowledge and skills to a chosen professional role. The student will work with a project and faculty advisor during this course. A comprehensive project proposal will be developed, shared, and reviewed; this proposal will serve as the foundation for implementation of the capstone project.

Semester 6 - Capstone II/ePortfolio (6 credits): With the guidance of project and faculty advisors, the student will implement and evaluate the project developed during Capstone I. A culminating ePortfolio will document the student's professional development throughout the e-learning degree completion program. 
further exploration of applicant understanding of the program's structure and demands.

Faculty development. For curricular change and innovation to occur, comprehensive faculty development programs need to be adopted. ${ }^{20}$ Faculty members need training to facilitate active learning activities incorporating the use of supportive technology, along with guidance in developing content that supports self-directed learning and critical thinking. ${ }^{20}$ Through regularly scheduled professional development sessions, faculty members can focus on understanding the need for change, becoming prepared to teach in the new environment, and developing skills needed to assess learning in the new curriculum. ${ }^{20}$

Since most U-M dental hygiene faculty members did not have distance education teaching experience, individuals were invited to participate based on their content expertise and enthusiasm for contributing to the development of this program. Eight faculty members were chosen. Each was charged to be a group leader in the development of at least one online course in the new eleven-course curriculum. Faculty sessions were developed to provide educational theory, methodology, and technology-related skills necessary to facilitate online courses. An infusion of these professional development sessions took place throughout the year prior to launching the first cohort, with additional plans outlined for long-term sustainability.

\section{Phase Two: Strategic Decisions}

\section{Program Production}

Guiding principles and competencies. Phase two of the systems-oriented model was also a team initiative. In addition to the eight faculty team members, an instructional technology designer joined the development team at this time. This learning technology expert provided experience and guidance in best practices for online program and course development.

Focusing on the goals of the program ("keeping the end in mind"), the team developed twenty-three competencies in five domains: 1) Leadership and Professional Development; 2) Information Literacy and Communication; 3) Health Promotion and Disease Prevention; 4) Evidence-Based Practice; and 5) Community. The competencies provided the foundation for specific course development. In addition, the team used two key principles related to educating future leaders: 1) dental educators are responsible to prepare students to be responsive to societal needs, utilize evidence-based decision making, serve as leaders in our evolving health care system, and be committed lifelong learners; $;{ }^{21}$ and 2) through the integration and application of knowledge, twenty-first-century workers and learners need to be able to utilize adaptive (transferable) expertise, function in collaborative environments, and become reflective practitioners. ${ }^{22}$

Critical thinking is the cornerstone for integrating these skills, allowing the student to raise questions, assess relevant information, think comprehensively, and communicate effectively to collaborate in determining solutions. ${ }^{21}$ To achieve this end, the following tenets were followed: andragogy (the teaching of adults, as opposed to pedagogy, the teaching of children), with a focus on active learning strategies (no recorded lectures or teleconferencing), would be applied in all courses; development of an integrated curriculum that would allow content to be connected among courses, linked to prior knowledge, and setting the stage for knowledge yet to be learned; ${ }^{23}$ assessment of learning outcomes would be through application (papers, projects, discussions, field experiences, etc.) and not tests and quizzes; and the professional skill of reflective practice would be integrated throughout the curriculum.

Course development. The individual e-learning course development process also embraced the systems-oriented model team approach. The course director (a content expert faculty member) led the development with the instructional designer and program directors as a consistent source of support. Content topic areas and learning outcomes had already been determined by the development team. With "keeping the end in mind," an Understanding by Design (UbD): Backward Course Design method was utilized. This method focuses on the difference between understanding and knowledge, determining key ideas worth understanding, and acknowledging when students have attained this understanding. ${ }^{24}$

Using backward course design. In backward course design, the educator begins by determining what the students will be able to do when the course is completed and how this will be assessed and then develops appropriate activities to determine what material needs to be covered..$^{24,25}$ Kelting-Gibson studied backward course design in comparison to more traditional classroom design methods and found that educators using backward design were more effective in developing courses that set clear 
goals and providing learning activities that supported those goals. ${ }^{26}$

Utilizing backward course design best practice was a challenge to the e-learning faculty members who had previously taught using traditional (fiftyyear-old standard) course techniques. Although dental hygiene education is competency (outcomes)based, the inclination of individual instructors was to focus on content delivery through readings and lectures, not on learning outcomes through assignments and activities. With the guidance of the instructional designer, course development groups worked through this process for six months prior to launching a course. This included bimonthly meetings that allowed for all phases of backward course design to be accomplished. A template outlining a framework for e-learning course components was developed that included division of course content into a module format. Each module included content, readings, and assignments/activities. Once course components were finalized, the group created grading rubrics for assignments.

Identifying ideal course models. During the development of the e-learning program curriculum, three course models emerged:

- Model 1: A course that introduced new content/ concepts on a weekly basis. This format also allowed for initial skill-building in the areas of discussion, reflection, and utilization of software such as PowerPoint.

- Model 2: A course that involved one large project. This allowed components of the project, and associated assignments, to be addressed on a weekly basis until the project was completed by the end of the course.

- Model 3: A "practical" course that could include a placement in a community agency or dental hygiene educational program but also incorporated a smaller weekly online didactic element.

Quality control. One month prior to each of the eleven new courses beginning, a prototype review was completed to ensure that the content, readings, and assignments/activities were understandable to people other than the course designers. This review also offered the opportunity to make sure that the course website's technology and associated links were functioning appropriately. Reviewers consisted of eight development team faculty members, the instructional designer, and four students from another online degree completion program. Review forms for each group were developed referencing concepts from the Institute for Higher Education Policy Qual- ity on the Line: Benchmarks for Success in InternetBased Distance Education..$^{27}$ Upon completion of the prototype review, the course director utilized feedback to make final revisions to the course. A best practice in distance education is the incorporation of this type of quality control. Not only does it play a critical role in evaluating course quality, but it can also be used as an assessment process in determining programmatic improvement. ${ }^{27}$

The courses, formatted in seven-week minimesters and taken one at a time, provided a perfect conduit for an integrated curriculum. Through integration, emphasis can be placed on learning and organizational skills needed to understand content; it progresses with topics sequenced and threaded to allow for scaffolded learning. ${ }^{23}$ However, students needed to be provided with a mechanism to have time to process and understand what they have learned and determine how it would be integrated within their next course and beyond. Portfolios have the utility for doing so.

Integrating an ePortfolio. A unique feature of the U-M e-learning portfolio is the "portfolio thinking" that is woven throughout the curriculum. Portfolio thinking is characterized by self-awareness of personal value, responsibility, and contribution. ${ }^{28}$ At the end of each course, the students utilize an electronic portfolio (ePortfolio) matrix that is housed within the CMS. The matrix includes the twenty-three e-learning competencies that can be accessed with each course number. Students are asked to write short reflections on four competencies they felt were most meaningful during that course.

Students do not typically enter the program with mature reflective writing skills. Student skillbuilding took place through reflective assignments within courses and the integration of ePortfolio assignments within each course. Reflections within the ePortfolio matrix utilize guiding questions to assist students in scaffolding their thinking and responses. The guiding questions include the following: 1) tell us about your experience with this competency in this moment: describe your current level of competence, recent experiences with this competency, etc.; 2) make connections: for example, how has your experience or understanding of this competency changed since you last wrote about it? What are your goals for further developing in this competency? What are your specific plans to do so?; and 3) artifact (examples of work) details: if you are including an artifact (examples of work include items such as papers, worksheets, projects, presentations, discussion form 
entry, etc.) to support this competency, please explain specifically how the artifact supports it. In addition to the matrix, the students complete a final reflection essay for each course that looks at "big picture" questions, such as how the course's topics relate to students' experience in their jobs or class projects.

Before the next course begins, the course development group crafts a question that draws on student responses to the final reflection question and asks students to apply knowledge from the recently completed course to the next seven-week course. Students and faculty members discuss this question together in an online forum during the first week of the new course. This bridging discussion helps place both the recently completed and upcoming course in context, reminding students every seven weeks to keep sight of the whole of their degree completion program.

Preparing the faculty. Faculty development is critical in promoting academic excellence..$^{29}$ Providing faculty members with the appropriate development opportunities focuses on improved teaching performance and better outcomes for students. ${ }^{29}$ While e-learning faculty members had enthusiasm for their involvement in the new program development as well as content expertise, online courses and integrative teaching were new arenas for them. Faculty development workshop sessions focused on best practices in distance education, guiding students' reflective writing, and providing feedback. These were delivered through a variety of mechanisms such as large group, small team, and individual sessions and provided a continuous opportunity for support and feedback for faculty members. Workshop topics included the following:

- Group technology sessions focusing on advancing familiarity with the university's course management system including format and function of the program's course website.

- One-on-one experiential sessions in backward course design with the instructional designer individually during the early stages of course development to assist individual faculty members in understanding this process and focusing on the key elements in creating an effective course and assessment rubrics.

- Group familiarization sessions with the university's online support resources including sessions with the health sciences librarian and writing center staff to ensure faculty members understood what resources were available and how these resources could support the students and faculty throughout the program.
- Group and small team course facilitation sessions including the role of the faculty member as course facilitator rather than content expert, tracking and grading discussion forums, appropriate faculty presence within discussion forums, time management, and providing effective feedback.

- Individualized sessions:

- New course launch: the e-learning program director and the course director scheduled weekly one-on-one meetings that allowed faculty members to clarify processes, expectations, and functions of technology.

o Writing assessment and feedback: as initial writing assignments came due within each course, the course director met with faculty members at the university's writing center to work through calibrated feedback and assessment of these papers using the grading rubric.

- Group and small team grading of reflective writing sessions. Faculty skill-building in the area of calibrated feedback on reflective writing assignments was imperative. Development sessions were spent on discussing reflection, what constitutes "good" reflection, how to assess and provide feedback, and the role of the integrative ePortfolio. Although reflective assignments within individual courses were graded by course directors, the ePortfolio reflective assignments at the end of each course were graded by a faculty team.

\section{Program Implementation}

Prior to beginning the e-learning program, students were required to attend a two-day on-campus orientation. During this event, laptops were distributed, and students were introduced to the university's educational support resources including the Health Sciences Libraries and campus writing center; Course Management System (CMS, CTools); expectations of discussion forums, professional writing, and the reflective ePortfolio; and assessment of their perceptions of online learning. Like the upcoming courses, orientation sessions were delivered in an interactive, application-based format allowing students to participate in practice discussions, reflections, professional writing vignettes, and online database searches while gaining experience using the CMS. Time was also interwoven throughout the two days for socialization. Students had the opportunity to get to know each other and their faculty members as well as time to tour and explore the university's campus.

Providing students with communication from the faculty before a course begins is critical. Three 
weeks prior to a course beginning, an e-mail is sent by the course director announcing required textbooks, dates the course will be running, and an introductory biosketch of the faculty member. Three days prior to any e-learning course start date, an "open house" becomes accessible to the students, in which selected areas of the course site are made available, including a link to the syllabus. A course orientation module provides an introductory overview of the course focus, alerts students to any assignments that may require longer term preparation, and provides information on the library, writing center, and professional writing resources.

\section{Program Evaluation and Revision}

Ongoing program evaluation was a goal from the onset of the project. Comprehensive program evaluation consisted of both qualitative and quantitative evaluation from all stakeholders. Evaluation was integrated throughout the program with analysis of outcomes assessment taking place at least quarterly by the faculty team. As a result of outcomes assessment, some change was anticipated. This regular analysis allowed for issues to be identified early and appropriate modifications made throughout the students' progress through the program. Qualitative evaluation included prototype review of courses prior to start date; reflection-related feedback: ePortfolio, discussion forums, and critical incident/ reflective journals that allowed for student critical self-assessment of their learning (this allowed for assessment of gaps in course content as well); feedback from community field experience, teaching practicum placement, and capstone project advisors/ faculty; open-ended questions about students' satisfaction with the program in each course evaluation; student focus group sessions conducted just prior to graduation; and faculty focus group sessions conducted after graduation. Quantitative evaluation included assignments, grades, course evaluations, and surveys (perceptions of online learning and orientation evaluation), as well as student publications and professional presentations tracking and quantification.

An example of a change made as a result of early program evaluation was related to the ePortfolio. Time was devoted during orientation to delivering information on its purpose and expectations, with an opportunity for students to participate in a reflective entry practice exercises. In the early courses, it became apparent that collectively the students'
ePortfolio entries were not satisfactory and that the training provided at orientation was insufficient. Utilizing anonymous student examples of excellent, satisfactory, and unsatisfactory ePortfolio reflections, a discussion forum was added in course 5 allowing students to individually use the grading rubric, provide their point value assessment for entries, and include supporting comments related to the point value they had assigned. Students uploaded completed rubrics to the discussion forum where, with the guidance of the course director, they discussed their outcomes. The result of this intervention provided a much deeper understanding of the ePortfolio process and resulted in much deeper reflections by the students. In addition to the ePortfolio introduction session at orientation, this model was subsequently integrated into course 1 to train Cohort 2 students. Cohort 2 reflections were much higher quality than Cohort 1's reflections in early courses, suggesting that the new portfolio training was more effective than the original version.

\section{Indicators of Success and Expected Changes}

The benchmarking process and program framework development research provided the conduit for making important strategic decisions based on best practices during phase two of the systems-oriented model (program production, implementation, and evaluation). An overview of the needs and challenges addressed in phase one and the resulting strategic decisions implemented in phase two are presented in Table 4. As implementation and evaluation occurred, adjustments to course content and assignments were expected, but, surprisingly, very little change has occurred thus far to the original courses. Both student and faculty feedback has been tracked, and integration of minor course-related modifications has taken place. Students and faculty members have indicated satisfaction with course content, program sequencing, online delivery method, and its associated technology. Comprehensive programmatic evaluation analysis and reporting will take place upon program completion by the first two cohorts.

Teaching in an online environment requires a specialized educational methodology, technology, and delivery skill set. Courses within the e-learning program are currently dependent upon those faculty members who have been involved with the program's development and have participated in the faculty training. There is a need for additional faculty mem- 


\section{Table 4. E-learning program: phase one to phase two overview}

Dimensions of Learning Environmen

Underlying Frameworks and Approaches to Learning

Timing of Course Delivery

Structure of Learning Community

Instructional Design

Faculty Recruitment, Development and Support

\section{Program Evaluation}

Programmatic and Administrative Needs

Technology
- Integration of six focus areas of ADHA

- Educate lifelong learners and reflective

practitioners capable of critical thinking

- Prepare 21 st century learners and leaders

- Two-year time frame is ideal

- Need to adapt to working students

- Limited number of degree completion programs geographically accessible to professional population

- Facilitate autonomous learning and learners

- Support collaborative and peer-based learning

- Build a community of practitioners that will continue after graduation

- Keeping the end in mind

- Collaborative faculty approach to integrated curriculum

- Application and synthesis levels of assessment

- Competency-based curriculum

- Faculty willingness to teach in distance education environment

- Faculty without online teaching experience

- New curriculum

- New delivery method

- Multifaceted approach to evaluate student, faculty and program outcomes

- Admissions and marketing

- Quality assurance

- Technology needs to support learning goals
- Build integrative and reflective curriculum

- Facilitate critical self-analysis

- Supported by ePortfolio

- Build asynchronous curriculum

- Focused courses in mini-mesters

- Facilitate enhancement of time management skills through module format within courses

- Student understanding of program time commitment

- Cohort-based

- Peer evaluation

- Group projects

- Discussion forums

- Backward course design

- Systems-oriented model

- Active learning assignments and activities

- Integration of ePortfolio

- Invitation to faculty with content expertise and willingness to pioneer new teaching and learning environment

- Robust faculty professional development program

- Development of evaluation plan before program launch

- Utilization of a variety of evaluation methods (course evaluations, ePortfolio, surveys, focus groups, etc.)

- Qualitative and quantitative evaluation at regular intervals, including program completion

- Admissions and marketing plans that include data collection and outcomes assessment

- Prototype review of courses prior to launch

- Technology chosen that facilitated student learning.

- Admissions process includes assessment of students technology skills 
bers who are willing to become involved in distance education to support the student enrollment growth of this program. A process for professional development training for these faculty members is currently being addressed.

\section{Lessons Learned}

Distance education can be a viable venue for implementing curricular change and expanding access to educational opportunities. Clearly established goals and learning outcomes for this change and rationale for the curricular delivery method should be based on professional need and rooted in best practices. A team-based, systematic plan for developing, implementing, and evaluating a program is critical to its success. There were important lessons learned from introducing the U-M Dental Hygiene Degree Completion E-Learning Program that served as a foundation for this process:

- Faculty enthusiasm, dedication, and desire to change were key. Inviting faculty members to participate and not mandating their involvement was important, if not essential, to program success. Providing appropriate professional development opportunities for faculty members to give feedback, learn from one another, and explore their questions and concerns was also critical.

- The systems-oriented model team approach was valuable in all phases of program development, course development, and evaluation. Identification of a program development team leader was important for coordination and management of this process.

- The backward course design method was essential for establishing clear goals and providing faculty members with a shared set of expectations and steps for developing their courses.

- A strong commitment is needed to applying active learning strategies in all courses along with regularly evaluating the impact of these strategies.

- Reflection should be defined as "critical selfassessment" and must be woven throughout the curriculum. Reflective practice skills need to be built from the beginning and refined throughout the program.

- A comprehensive program evaluation plan should be established early in the development phase and utilize both qualitative and quantitative methods. Results should be analyzed often, with faculty members prepared and willing to make modifica- tions and/or changes to improve student learning outcomes.

\section{REFERENCES}

1. Pyle M, Andrieu SC, Chadwick DG, Chmar JE, Cole JR, George MC, et al. The case for change in dental education. J Dent Educ 2006;70(9):921-4.

2. Kalkwarf KL, Haden NK, Valachovic RW. ADEA Commission on Change and Innovation in Dental Education. J Dent Educ 2005;69(10):1085-7.

3. American Dental Hygienists' Association. Standards for clinical dental hygiene practice. Chicago: American Dental Hygienists' Association, 2008.

4. Newell KJ, Stoltenberg JL, Osborn JB, Peterson MD. Dental hygiene student interest in advanced education. J Dent Hyg 1989;63(6):276-82.

5. Commission on Dental Accreditation. Accreditation standards for dental hygiene education programs, 2010. At: www.ada.org/sections/educationAndCareers/pdfs/dh.pdf. Accessed: June 1, 2010.

6. Waring MB. Factors affecting participation in external degree completion programs. J Dent Hyg 1991;65(2):80-90.

7. Monson AL, Engeswick LM. ADHA's focus on advancing the profession: Minnesota's dental hygiene educator's response. J Dent Hyg 2007;81(2):5-11.

8. Nunn PJ, Gadbury-Amyot CC, Battrell A, Bruce SI, Hanlon LL, Kaiser C, Purifoy-Seldon B. The current status of allied dental faculty: a survey report. J Dent Educ 2004;68(3): 329-44.

9. American Dental Association. Dental education programs. At: www.ada.org/267.aspx. Accessed: April 10, 2010.

10. American Dental Hygienists' Association. Dental hygiene programs. At: www.adha.org/careerinfo/dir_education. htm. Accessed: April 10, 2010.

11. Grimes EB. Use of distance education in dental hygiene programs. J Dent Educ 2002;66(10):1136-45.

12. Gustafson KL, Branch RM. Survey of instructional development models. $4^{\text {th }}$ ed. ERIC Document Reproduction Service No. ED477517. Syracuse, NY: ERIC Clearinghouse on Information and Technology, 2002.

13. Bristol TJ. Evidence-based e-learning for nurse educators. Des Moines: Center for Health Workforce Planning, Bureau of Health Care Access, Iowa Department of Public Health, 2006.

14. Piskurich GM. Preparing learners for e-learning. San Francisco: Jossey-Bass/Pfeiffer, 2003.

15. Siefert K, Mandzuk D. Student cohorts in teacher education: support groups or intellectual communities? Teach Coll Record 2006;108(7):1296-320.

16. Davis BJ. Distance learning: educated choices or educational technoism? ERIC Document Reproduction Service No. ED478776. Syracuse, NY: ERIC Clearinghouse on Information and Technology, 2003.

17. Illinois Online Network, University of Illinois. Weaknesses of online learning, 2010 At: www.ion.uillinois.edu/ resources/tutorials/overview/weaknesses.asp. Accessed: March 24, 2010.

18. American Dental Hygienists' Association. Dental hygiene: focus on advancing the profession. Chicago: American Dental Hygienists' Association, 2005. 
19. Willging PA, Johnson SD. Factors that influence students' decision to drop out of online courses. J Asynchronous Learn Networks 2004;8(4):105-18.

20. Licari FW. Faculty development to support curriculum change and ensure the future vitality of dental education. J Dent Educ 2007;71(12):1509-12.

21. Haden NK, Andrieu SC, Chadwick DG, Chmar JE, Cole JR, George MC, et al. The dental education environment. J Dent Educ 2006;70(12):1265-70.

22. Stewart L, Dahm E. $21^{\text {st }}$ century skills for $21^{\text {st }}$ century jobs: a report. Washington, DC: U.S. Department of Commerce, Department of Education, National Institute of Literacy, Small Business Administration, 1999.

23. Kysilka ML. Understanding integrated curriculum. Curriculum J 1998;9(2):197-209.
24. Wiggins G, McTighe J. Understanding by design. $2^{\text {nd }}$ ed. Alexandria, VA: Association for Supervision and Curriculum Development, 2005.

25. Daughtery KK. Backward course design: making the end the beginning. Am J Pharm Educ 2006;70(6):e1-5.

26. Kelting-Gibson LM. Comparison of curriculum development practices. Educ Res Q 2005;29(1):26-36.

27. Institute for Higher Education Policy. Quality on the line: benchmarks for success in Internet-based distance education. Washington, DC: Institute for Higher Education Policy, 2000.

28. McLagan PA. Portfolio thinking. Train Dev 2000;54(2): 44-51.

29. Hendricson WD, Anderson E, Andrieu SC, Chadwick DG, Cole JR, George MC, et al. Does faculty development enhance teaching effectiveness? J Dent Educ 2007;71(12): 1513-33. 